trong điêu trị nội trú bệnh viêm phổi do vi khuẩn cho trẻ em có BHYT tại Bệnh viện Nhi Lâm Đồng giai đoạn 2019-2020. Đây là những thông tin cân thiết để hoạch định chính sách, giúp bệnh viện có sự chuẩn bị về nguồn lực để nâng cao chất lượng dịch vụ khám chữa bệnh và tập trung nguồn lực vào các vấn đề ưu tiên. Các nghiên cứu tiếp theo có thể mở rộng phạm vi tính toán chi phí trong điều trị ngoại trú.

\section{TÀI LIẸU THAM KHẢO}

1. WHO (2018), Revised WHO classification and treatment of childhood pneumonia at health facilities, pp. 2-4.

2. Jain S, Seema Jain, Derek J. Williams (2015). Community-acquired pneumonia requiring hospitalization among U.S. children. N. Engl. J. Med. 372, pp. 835-845.

3. Bệnh viện Nhi Lâm Đồng (2020), Báo cáo tổng kết hoạt động bệnh viện giai đoạn 2019-2020.

4. Bui Thi Xuan, Pham Van Dem, Hoang Van Hung (2019). Analysis of cots for children treatment pneumonia in Bach Mai Ha Noi hospital from $10 / 2018$ to $3 / 2019$. VNU Journal of Science: Medical and Pharmaceutical Sciences, vol 35, n.2, pp. 96-104.

5. Alexander KC Leung, Alex HC Wong, Kam L Hon (2018). Community-Acquired Pneumonia in Children. Recent Patents on Inflammation \& Allergy Drug Discovery, Volume 12, Number 2, pp. 136-144.

6. Nguyen TK Phuong, Tran T Hoang, Pham H Van, Lolyta Tu, Stephen M Graham, Ben J Marais (2017). Encouraging rational antibiotic use in childhood pneumonia - focus on the Western Pacific region. PMC pneumonia, pp. 7-9.

7. Berce $V$, Tomazin $M$, Gorenjak $M$, Berce $T$, Lovrenčič B (2019). The Usefulness of Lung Ultrasound for the Aetiological Diagnosis of Community-Acquired Pneumonia in Children. Sci Rep, 9(1).

\title{
NÔNG Độ 25 (OH)D HUYẾT THANH Ở TRẺ EM VIÊM PHỔI TẠI BỆNH VIỆN NHI TRUNG ƯO'NG
}

\section{TÓM TẮT}

Vitamin $D$ có vai trò quan trong trong khả năng đề kháng của cơ thể. Mục tiêu: Khảo sát nồng độ 25 $(\mathrm{OH}) \mathrm{D}$ huyết thanh ở trẻ em viêm phổi và mối liên quan giữa nông độ $25(\mathrm{OH}) \mathrm{D}$ và mức độ nặng của viêm phổi. Phương pháp nghiên cứu: Nghiên cứu tiến cứu mô tả cắt ngang trên 84 bệnh nhân viêm phổi từ tháng 8 năm 2020 đến tháng 7 năm 2021 tại Khoa điều trị tự nguyện - Bệnh viện Nhi Trung Ương. Kết quả: Tuổi trung bình của bênh nhân $14,6 \pm 10,5$ tháng, viêm phổi nặng chiếm tỷ lệ 20,2\%. Nồng độ $25(\mathrm{OH}) \mathrm{D}$ trung bình là $91,8 \pm 41, \overline{7} \mathrm{nmol} / \mathrm{l}$ (dao động từ 29,1 nmol/l - là 261,6 nmol/l). Nồng độ $25(\mathrm{OH}) \mathrm{D}$ < 50 nmol/l chiếm tỷ lệ 11,9\%; từ 50 - 75 nmol/ I chiếm tỷ lệ $23,8 \%$; >75 nmol/l chiếm tỷ lệ $64,3 \%$. Nồng độ $25(\mathrm{OH}) \mathrm{D}$ thấp có nguy cơ mắc viêm phổi năng. Thời gian nằm viện kéo dài hơn ở trẻ có nồng độ 25(OH)D thấp. Kết luận: Trẻ viêm phổi có nồng đổ $25(\mathrm{OH}) \mathrm{D}$ thấp có nguy cơ bi viêm phổi nặng hơn nhóm có nồng độ 25(OH)D bình thường.

Tư khoá: viêm phôi, viêm phổi nặng, nồng độ 25(OH)D.

\section{SUMMARY \\ CONCENTRATION OF SERUM 25 (OH)D IN CHILDREN WITH PNEUMONIA AT THE}

\footnotetext{
${ }^{1}$ Trường Đại học Y Hà Nội

Chịu trách nhiệm chính: Nguyễn Thị Diệu Thúy

Email: nguyendieuthuyhmu@gmail.com

Ngày nhận bài: 10.5.2021

Ngày phản biện khoa học: 2.7.2021

Ngày duyệt bài: 12.7.2021
}

Sitthixay Phounsavath ${ }^{1}$, Nguyễn Thị Diệu Thúy ${ }^{1}$

\section{NATIONAL CHILDREN'S HOSPITAL}

Vitamin D plays an important role for health status. Objectives: To assess the concentration of serum $25(\mathrm{OH}) \mathrm{D}$ in children with pneumonia and the relationship between the serum 25(OH)D concentration and the severity of pneumonia. Methods: A cross-sectional descriptive prospective study in 84 children with pneumonia from August 2020 to July 2021 at the Vietnam National Children's Hospital. Results: The average age of children was $14.6 \pm 10.5$ months, with severe pneumonia accounting for $20.2 \%$. The concentration of $25(\mathrm{OH}) \mathrm{D}$ was $91.8 \pm 41.7 \mathrm{nmol} / \mathrm{l}$ (ranged from $29.1 \mathrm{nmol} / \mathrm{l}$ to $261.6 \mathrm{nmol} / \mathrm{l})$. The prevalance of children with $25(\mathrm{OH}) \mathrm{D}$ concentration < $50 \mathrm{nmol} / \mathrm{l}$ was $11.9 \%$. Low concentrations of $25(\mathrm{OH}) \mathrm{D}$ related to a risk of severe pneumonia. Longer hospital stay in children with low 25(OH)D concentrations. Conclusion: Children with low 25(OH)D concentrations have a high risk of severe pneumonia and a longer hospitalised stay.

Keywords: pneumonia, severe pneumonia, 25(OH)D concentrations.

\section{I. ĐĂT VẤN ĐỀ}

Theo Tổ chức $Y$ tế Thế giới (WHO), viêm phổi là nguyên nhân hàng đâu gây tử vong ở trẻ em. Có nhiều yếu tố làm tăng nguy cơ gây viêm phổi hoăc làm tăng mức độ nặng của viêm phổi, trong đó thiếu vitamin $\mathrm{D}$ là yếu tố được đề cập nhiều trong thời gian gần đây. Thiếu vitamin $D$ ngoài việc gây ra bệnh còi xương còn liên quan đến tình trạng nhiễm trùng đường hô hấp tái đi tái lại [1]. Các công trình nghiên cứu đã chứng 
minh rằng Vitamin $D$ ngoài vai trò trong chuyển hóa $\mathrm{Ca}$, còn có vai trò đặc biệt quan trọng trong việc kích hoạt hệ thống miễn dịch bẩm sinh và mắc phải. Dạng hoạt động của Vitamin $\mathrm{D}$ là 1,25 $(\mathrm{OH})_{2} \mathrm{D}$ kích thích hoạt động chống vi khuẩn của các tế bào đơn nhân và đại thực bào[2]. Các nghiên cứu đã chứng minh rằng vitamin $\mathrm{D}$ giúp tạo ra các peptide kháng khuẩn, tăng cường tiêu diệt các vi khuẩn Mycobacterium tuberculosis nội bào (thường gặp nhất trong lao phổi). Ở Việt Nam cho đến nay đã có một số nghiên cứu về vai trò của vitamin $D$ trong các bệnh lý mạn tính như hen phế quản, viêm khớp mãn tính cũng như một số bệnh cấp tính như suy dinh dưỡng, tiêu chảy cấp. Tuy nhiên nghiên cứu mối liên quan giữa nồng độ Vitamin $D$ và một số bệnh nhiễm khuẩn cấp tính còn chưa được đề câp nhiều. Viêm phổi là bệnh lý nhiễm khuẩn cấp thường gặp ở trẻ em, vì vậy chúng tôi tiến hành nghiên cứu với mục tiêu "Khảo sát nồng độ 25 $(O H) D$ huyết thanh ở trẻ em viêm phổi và nhân xét mối liên quan giữa nồng độ $25(\mathrm{OH}) D$ và mức độ nặng của viêm phổi".

\section{II. ĐỐI TƯợNG VÀ PHƯƠNG PHÁP NGHIÊN CỨU \\ Đối tượng nghiên cứu}

*Tiêu chuẩn lựa chọn: Bệnh nhân từ 1 tháng đến 5 tuổi được chẩn đoán xác định viêm phổi. Trẻ được định lượng nồng độ $25(\mathrm{OH}) \mathrm{D}$ trong máu. Gia đình đồng ý tham gia nghiên cứu

*Tiêu chuẩn loại trừ: Bệnh nhân viêm phổi do lao, HIV... Bệnh nhân có kèm theo các bệnh lý mạn tính như tim bẩm sinh, phổi bẩm sinh, bệnh lý gan mật...

Phương pháp nghiên cứu

Thiết kế nghiên cứu: Nghiên cứu tiến cứu mô tả cắt ngang. Nghiên cứu được tiến hành từ tháng 8 năm 2020 đến tháng 7 năm 2021 tại Khoa điêu trị tự nguyện $B$ - Bệnh viện Nhi Trung Ương.

Trong thời gian nghiên cứu, có 84 bệnh nhân viêm phổi được làm xét nghiệm $25(\mathrm{OH})$ D đủ tiêu chuẩn được mời tham gia nghiên cứu.

Phân tích và xử lý số liệu: Số liệu được thu thập và xử lý với phần mềm SPSS 20.0, sự khác biệt có có ý nghĩa thống kê với $p<0,05$.

Đạo đức nghiên cứu: Nghiên cứu tiến cứu, không can thiệp vào bệnh nhân. Các thông tin liên quan đến đối tượng nghiên cứu được giữ bí mật.

\section{KẾT QUẢ NGHIÊN CứU}

Có 84 trẻ viêm phổi đủ tiêu chuẩn tham gia nhiên cứu, với $20,2 \%$ viêm phổi nặng. Nồng độ $25(\mathrm{OH}) \mathrm{D}$ trung bình $91,8 \pm 41,7 \mathrm{nmol} / \mathrm{l}$, thấp nhất là $29,1 \mathrm{nmol} / \mathrm{I}$ và cao nhất là $261,6 \mathrm{nmol} / \mathrm{l}$.

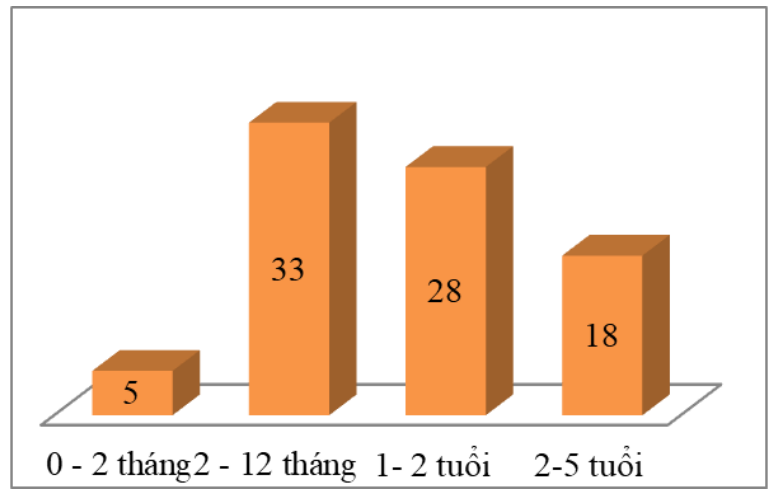

\section{Biểu đồ 1. Phân bố theo nhóm tuổi}

Nhân xét: Nhóm trẻ viêm phổi hay gặp nhất và nhóm dưới 12 tháng, chiếm tỷ lệ 45,2\%. Nhóm tuổi 2-5 tuổi chiếm tỷ lệ 21,4\%.

Bảng 1. Phân bố nồng độ 25(OH)D của đôî tượng nghiên cứu

\begin{tabular}{|c|c|c|}
\hline Nồng độ 25(OH)D & $\mathbf{n}$ & $\mathbf{\%}$ \\
\hline$<50(\mathrm{nmol} / \mathrm{I})$ & 10 & 11,9 \\
\hline $50-75(\mathrm{nmol} / \mathrm{I})$ & 20 & 23,8 \\
\hline$>75(\mathrm{nmol} / \mathrm{I})$ & 54 & 64,3 \\
\hline Tống & $\mathbf{8 4}$ & $\mathbf{1 0 0}$ \\
\hline
\end{tabular}

Nhận xét: Trẻ có nồng độ 25(OH)D thấp < $50 \mathrm{nmol} /$ I có 10 trẻ chiếm tỷ lệ11,9\%. Nồng độ $25(\mathrm{OH}) \mathrm{D} 50-75 \mathrm{nmol} / \mathrm{l}$ có 20 trẻ chiếm tỷ lể $23,8 \%$. Nồng độ $25(\mathrm{OH}) \mathrm{D}>75 \mathrm{nmol} / \mathrm{l}$ có 54 trẻ chiếm tỷ lệ 64,3\%.

Bảng 2. Mối liên quan sử dụng Vitamin D3 và mức độ nặng viêm phổi

\begin{tabular}{|c|c|c|}
\hline Tình trạng & $\begin{array}{c}\text { Sử dụng } \\
\text { Vitamin } \\
\text { D3 }\end{array}$ & $\begin{array}{c}\text { Không sử } \\
\text { dụng } \\
\text { Vitmain D }\end{array}$ \\
\hline Viêm phối & 53 & 14 \\
\hline Viêm phối nặng & 10 & 7 \\
\hline p & \multicolumn{2}{|c|}{$<0,05$} \\
\hline
\end{tabular}

Nhận xét: Có mối liên quan giữa sử dụng Vitamin $D$ và mức độ viêm phổi, sự khác biệt có ý nghĩa thống kê với $p<0,05$.

Bảng 3. Mối liên quan giữa nồng độ 25(OH)D với mức độ nặng viêm phổi

\begin{tabular}{|c|c|c|c|}
\hline $\begin{array}{l}\text { Nông đô } \\
\text { 25(OH)D }\end{array}$ & $\begin{array}{l}\text { Viêm } \\
\text { phổi }\end{array}$ & $\begin{array}{l}\text { Viêm } \\
\text { phổi } \\
\text { năng }\end{array}$ & p \\
\hline$<50 \mathrm{nmol} / \mathrm{l}$ & 2 & 8 & \multirow{3}{*}{$<0,05$} \\
\hline $\begin{array}{c}50-75 \\
\mathrm{nmol} / \mathrm{l}\end{array}$ & 11 & 9 & \\
\hline$>75 \mathrm{nmol} / \mathrm{l}$ & 54 & 0 & \\
\hline Tống & 67 & 17 & 84 \\
\hline
\end{tabular}

Nhận xét: Có mối liên quan giữa nồng độ $25(\mathrm{OH}) \mathrm{D}$ huyết thanh với mức độ nặng của viêm phổi. Nồng độ $25(\mathrm{OH}) \mathrm{D}$ thấp thì nguy cơ viêm phổi nặng cao, sự khác biệt có ý nghĩa thống kê với $p<0,05$. 
Bảng 4. Môi liên quan nồng độ 25(OH)D với thời gian nằm viện

\begin{tabular}{|c|c|}
\hline $\begin{array}{c}\text { Nồng đồ } \\
\mathbf{2 5}(\mathbf{O H}) \mathbf{D}\end{array}$ & $\begin{array}{c}\text { Thời gian nằm viện trung } \\
\text { bình (ngày) } \\
\text { (Min - Max) }\end{array}$ \\
\hline $\begin{array}{c}91,8 \pm 41,7 \\
\mathrm{nmol} / \mathrm{l}\end{array}$ & $8,3 \pm 2,4(5-16)$ \\
\hline$<75 \mathrm{nmol} / \mathrm{l}$ & $11,2 \pm 2,8(7-16)$ \\
\hline$\geq 75 \mathrm{nmol} / \mathrm{l}$ & $7,9 \pm 2,0(5-14)$ \\
\hline $\mathrm{p}$ & 0,002 \\
\hline
\end{tabular}

Nhân xét: Thời gian điều trị viêm phổi trung bình là $8,3 \pm 2,4$ ngày, ngắn nhất là 5 ngày và lâu nhất là 16 ngày. Trong đó thời gian nằm viện trung bình ở nhóm có nồng độ $25(\mathrm{OH}) \mathrm{D}<75$ nmol/l là $11,2 \pm 2,8$ ngày, ngắn nhất là 7 ngày và lâu nhất là 16 ngày. Trong khi đó thời gian nằm viện của nhóm bệnh nhân có nồng độ $25(\mathrm{OH}) \mathrm{D}>=75 \mathrm{nmol} / \mathrm{l}$ là $7,9 \pm 2,0$ ngày, ngắn nhất là 5 ngày và lâu nhất là 14 ngày, sự khác biệt có ý nghĩa thống kê với $p=0,002$.

\section{BÀN LUẬN}

Trong 84 trẻ viêm phổi tham gia nghiên cứu, tuổi trung bình của trẻ là 14,6 $\pm 10,5$ tháng, trẻ nhỏ nhất là 1 tháng và lớn nhất là 48 tháng. Nhóm tuổi gặp nhiều nhất từ $2-12$ tháng tuổi, chiếm tỷ lệ $39,3 \%$. Tiếp đến là trẻ từ $1-2$ tuối chiếm tỷ lệ $33,3 \%$. Kết quả này tương tự nghiên cứu của Vũ Thị Hương[3] với 77,9\% viêm phổi gặp ở trẻ dưới 2 tuổi. Năm 2012, Lê Văn Tráng[4] nghiên cứu 475 bệnh nhi viêm phổi từ 2 tháng đến 5 tuổi tại Bệnh viện Nhi Thanh Hóa cũng cho kết quả tương tự, với $62,7 \%$ là trẻ dưới 1 tuổi. Như vậy, trẻ dưới 24 tháng tuổi dễ mắc viêm phổi và đây cũng là nhóm tuổi phải nhập viện điều trị cao nhất. Điều này có thể giải thích bởi những đặc điểm giải phẫu và sinh lý hệ hô hấp ở trẻ nhỏ làm cho trẻ dễ mắc viêm phổi nặng và dễ tiến triển đến suy hô hấp.

Nghiên cứu chỉ ra viêm phổi mức độ nhe nhập viện gặp nhiều nhất chiếm tỉ lệ $79,8 \%$, viêm phổi nặng là $20,2 \%$. Thực tế nghiên cứu chỉ thực hiện tại khoa điều trị tự nguyện nên trẻ chủ yếu viêm phổi mức độ nhe. Nếu trẻ viêm phổi nặng, trẻ thường được điều trị tại các khoa chuyên sâu như Hô hấp hay Hồi sức cấp cứu.

Nồng độ $25(\mathrm{OH})$ D: Nồng độ $25(\mathrm{OH}) \mathrm{D}$ huyết thanh trung bình ở trẻ viêm phổi là 91,8 $\pm 41,7 \mathrm{nmol} / \mathrm{l}$, thấp nhất là $29,1 \mathrm{nmol} / \mathrm{l}$ và cao nhất là 261,6. Trong đó nồng độ 25(OH)D thấp $<50 \mathrm{nmol} / \mathrm{l}$ chiếm tỷ lệ $11,9 \%$, nồng độ $25(\mathrm{OH}) \mathrm{D}$ từ $50-75 \mathrm{nmol} / \mathrm{I}$ chiếm tỷ lệ $23,8 \%$ và nồng độ 25(OH)D > 75 nmol/l chiếm tỷ lệ $64,3 \%$. Kết quả này cũng tương tự nghiên cứu của Dinlen[5] với mức $25(\mathrm{OH})$ D trung bình là $9,5 \mathrm{ng} / \mathrm{mL}$ $(p=0,0001)$. Nghiên cứu của Mohamed[6] cũng cho thây $30,1 \%$ trẻ có nồng độ $25(\mathrm{OH}) \mathrm{D}$ thấp bị viêm đường hô hấp cấp trong 2 năm đầu đời, trong đó $79 \%$ trẻ bị viêm tiểu phế quản và $21 \%$ trẻ sơ sinh bị viêm phổi.

Mối liên quan việc sử dụng Vitamin D3 với viêm phổi: Nghiển cứu của chúng tôi cho thấy có mối liên quan giữa sử dụng vitamin $D$ và mức độ nặng của viêm phổi, sự khác biệt có ý nghĩa thống kê với $p<0,05$. Các trẻ được sử dụng vitamin D3 ít trường hợp chuyển viêm phổi nặng. Kết quả của chúng tôi cũng tương tự với nghiên cứu của McNally[7] cho thấy mức vitamin D trung bình của toàn bộ nhóm viêm đường hô hấp cấp tính được nhân vào phòng hồi sức tích là $49 \pm 24 \mathrm{nmol} / \mathrm{L}$ thấp hơn so với bệnh nhân được nhận vào khoa nhi tổng quát là $87 \pm 39$ nmol/L. Sự thiếu hụt vitamin $D$ liên quan đến tỷ lệ nhập viện chăm sóc đặc biệt ở trẻ em trong phân tích đa biến.

Mối liên quan nồng độ 25(OH)D với viêm phổi: Trong nhóm nghiển cứu có nồng độ $25(\mathrm{OH}) \mathrm{D}<50 \mathrm{nmol} / \mathrm{l}$ có 2 bệnh nhân viêm phổi, có 8 bệnh nhân viêm phổi nặng, sự khác biệt có ý nghĩa thống kê với $p<0,05$. Hơn nữa, cả 17 trường hợp viêm phổi nặng đều có nồng độ 25(OH)D giảm. Đặc biệt $8 / 17$ bệnh nhân nhóm này (chiếm $47,1 \%$ ) có nồng độ $25(\mathrm{OH}) \mathrm{D}$ $<50 \mathrm{nmol} / \mathrm{l}$. Như vậy, có thể thấy nồng độ $25(\mathrm{OH}) \mathrm{D}$ càng giảm thấp thì nguy cớ viêm phổi mức đô năng càng cao. Điều này có thể giải thích bởi thụ thể vitamin $\mathrm{D}$ có mặt trên các đại thực bào và tế bào lymphoT. $1,25(\mathrm{OH})_{2} \mathrm{D}$ tác động như một chất điều biến hệ thống miễn dịch, dự phòng hiện tượng giải phóng quá thừa các cytokine gây viêm và làm tăng "sự bùng nổ oxy hóa" của các đại thực bào. Điều quan trọng nhất là vitamin $\mathrm{D}$ kích hoạt các peptid kháng khuẩn (cathelicidin và beta-defensin 2 ) có mă̆t trong các bạch câu đa nhân trung tính, bạch cầu đơn nhân, tế bào diệt tự nhiên và trong các tế bào biểu mô lát đường hô hấp, nơi mà các tế bào này đóng vai trò chính bảo vệ cơ thể chống lại vi khuẩn, virus và nấm. Nghiên cứu của Oduwole [8] ghi nhận $54 \%$ bệnh nhân nhi viêm phổi có nồng độ $25(\mathrm{OH}) \mathrm{D}$ huyết thanh nhỏ hơn $70 \mathrm{nmol} / \mathrm{L}$ và $46 \%$ có nồng độ $25(\mathrm{OH}) \mathrm{D}$ huyết thanh lớn hơn $70 \mathrm{nmol} / \mathrm{L}$. Hạ canxi máu thường xuyên hơn ở những đối tượng có $25(\mathrm{OH}) \mathrm{D}$ dưới $70 \mathrm{nmol} / \mathrm{L}$ so với những người trên $70 \mathrm{nmol} / \mathrm{L}$ ( $\mathrm{p}$ $=0,01)$. Tràn dịch màng phổi và tử vong thường xảy ra ở nhóm bệnh nhi có nồng độ $25(\mathrm{OH}) \mathrm{D}$ từ 27,5 đến $40 \mathrm{nmol} / \mathrm{L}$. Thiếu máu thường xuyên 
hơn ở những đối tượng có $25(\mathrm{OH})$ D dưới 70 $\mathrm{nmol} / \mathrm{L}$ so với trẻ trên $70 \mathrm{nmol} / \mathrm{L}(\mathrm{p}=0,03)$.

Mối liên quan nồng độ 25(OH)D với thời gian nằm viện. Thời gian nằm viện trung bình là $8,3 \pm 2,4$ ngày, ngắn nhất là 5 ngày và lâu nhất là 16 ngày. Trong đó thời gian nằm viện trung bình ở nhóm có nồng độ 25(OH)D < 75 nmol/l là 11,2 \pm 2,8ngày (7 - 16ngày). Thời gian nằm viện của nhóm bệnh nhân có nồng độ $25(\mathrm{OH}) \mathrm{D} \geq 75 \mathrm{nmol} / \mathrm{l}$ là $7,9 \pm 2,0$ ngày $(5-14$ ngày), sự khác biệt có ý nghĩa thống kê với $p=$ 0,002 . Nghiên cứu của chúng tôi gặp 9 bệnh nhân viêm phổi nặng đều có nồng độ $25(\mathrm{OH}) \mathrm{D}$ < 75 nmol/l cân điều trị hỗ trợ hô hấp và sử dụng kháng sinh dài ngày nên việc điêu trị cân thời gian nằm viện cao hơn.

\section{KẾT LUÂ̂N}

Vitamin $D$ có liên quan đến mức độ nặng của viêm phổi. Trẻ ít được bổ sung Vitamin $D$ và có nồng độ $25(\mathrm{OH}) \mathrm{D}$ thấp có nguy cơ bị viêm phổi nặng hởn, có thời gian điều trị kéo dài hơn.

\section{TÀI LIẸU THAM KHẢO}

1. Yakoob MY, et al.(2016). Vitamin D supplementation for preventing infections in children under five years of age. Cochrane
Database of Systematic Reviews. 11),

2. Das RR, et al.(2013). Vitamin d supplementation for the treatment of acute childhood pneumonia: a systematic review. ISRN Pediatr. 2013(459160-.

3. Vũ Thị Hướng (2018). Nghiên cứu nguyên nhân viêm phổi ở trẻ em dưới 5 tuổi tại Khoa Tự Nguyện Bênh Viện Nhi Trung Ương. Luận án văn Thạc sỹ Y học, Trường Đại học Y Hà nội.

4. Lê Văn Tráng (2012). Nghiên cứu tính kháng kháng sinh trong viêm phổi do vi khuẩn ở trẻ em tai bệnh viện Nhi Thanh Hóa. Luận văn bác sỹ chuyển khoà cấp II, Trường Đại học Y Hà Nội.

5. Dinlen $\mathbf{N}$, et al.(2016). Association of vitamin $D$ deficiency with acute lower respiratory tract infections in newborns. The journal of maternalfetal \& neonatal medicine: the official journal of the European Association of Perinatal Medicine, the Federation of Asia and Oceania Perinatal Societies, the International Society of Perinatal Obstet. 29(6), 928-32.

6. Mohamed WA, Al-Shehri MA(2013). Cord blood 25-hydroxyvitamin D levels and the risk of acute lower respiratory tract infection in early childhood. Journal of tropical pediatrics. 59(1), 29-35.

7. McNally JD, et al.(2009). Vitamin D deficiency in young children with severe acute lower respiratory infection. Pediatric pulmonology. 44(10), 981-8.

8. Oduwole AO, et al.(2010). Relationship between vitamin D levels and outcome of pneumonia in children. West African journal of medicine. 29(6), 373-8.

\section{TÌNH TRẠG DINH DƯỡNG CỦA TRẺ EM MẮC BÊ̂NH RUộT VIÊM TẠI BỆNH VIỆN NHI TRUNG ƯƠNG}

\section{TÓM TẮT}

Suy dinh dưỡng và chậm phát triển là những biểu hiên chính ngoài đường tiểu hóa trong bênh ruột viêm trẻ em. Mục tiêu: mố tả tình trạng dinh dưỡng của trẻ em mắc bệnh ruột viêm tại bệnh viện Nhi trung ương. Đối tướng và phương pháp: nghiên cứu mô tả loạt ca bệnh gồm 31 trẻ mắc bệnh ruột viêm điều trị tại bênh viên Nhi trung ương từ 01/07/2020 đến 31/03/2021. Kết quả: Tỷ lệ mắc bênh ở trẻ trai và trẻ gái là $1,6: 1$. Tuổi mắc bệnh trung bình là $48,0 \pm 50,3$ tháng. $42 \%$ trẻ suy dinh dưỡng thể thấp còi, trong đó mức đô vừa và năng lần lướt là $19,4 \%$ và $22,6 \%$. $35,5 \%$ trẻ suy dinh dưỡng thể nhẹ cân $(9,7 \%$ nhẹ cân vữa và $25,8 \%$ nhe cân nặng). $25,8 \%$ trẻ có thiếu máu. Tỷ lệ trẻ thiếu calci và thiếu sắt lần lượt là

\footnotetext{
${ }^{1}$ Trường Đại học Y Hà Nọi

²Bênh viện Nhi Trung Ương

Chịu trách nhiệm chính: Nguyễn Thị Việt Hà

Email: vietha@hmu.edu.vn

Ngày nhận bài: 11.5.2021

Ngày phản biện khoa họ: 1.7.2021

Ngày duyệt bài: 12.7.2021
}

\section{Phan Thị Hồng Hải ${ }^{1}$, Nguyễn Thị Việt Hà ${ }^{1,2}$}

$90,3 \%$ và $70 \%$. $34,6 \%$ trẻ có giảm vitamin $D$ và $50 \%$ có thiếu kẽm. Kết luận: Trẻ em mắc bệnh ruột viêm có tỷ lệ suy dinh dưỡng cao trong đó thiếu yểu tố vi lượng là các biểu hiện thường gặp.

\section{SUMMARY}

\section{NUTRITIONAL STATUS IN CHILDREN WITH INFLAMMATORY BOWEL DISEASE AT THE NATIONAL CHILDREN'S HOSPITAL}

Malnutrition and growth retardation are the main extraintestinal manifestations of inflammatory bowel disease in children. Aim: to describe a nutritional status in children with inflammatory bowel disease. Materials and methods: a case series included 31 patients diagnosed inflammatory bowel disease at the National Children's Hospital from July 2020 to March 2021. Results: Morbidity rate of male/female was $1,6: 1$. The mean age at onset of symptoms was 48,0 $\pm 50,3$ months. $42 \%$ children were growth retardation, of which $22,6 \%$ children were severe malnutrition. $35,5 \%$ of children were underweight. Among them, moderate and severe malnutrition was $9,7 \%$ and $25,8 \%$, respectively. Anemia was observed in $25,8 \%$ children. Prevalence of calcium and iron 